\title{
Treatment Outcomes of Endovascular Embolization Only in Patients with Unruptured Brain Arteriovenous Malformations: A Subgroup Analysis of ARUBA (A Randomized Trial of Unruptured Brain Arteriovenous Malformations)
}

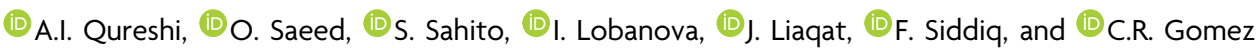

\begin{abstract}
BACKGROUND AND PURPOSE: Endovascular embolization only has been advocated for treatment of brain arteriovenous malformations in recent trials. Our aim was to evaluate the results of embolization only in a cohort of patients who were enrolled in the A Randomized Trial of Unruptured Brain Arteriovenous Malformations (ARUBA) study at 39 clinical sites in 9 countries.
\end{abstract}

MATERIALS AND METHODS: We analyzed the rates and severity of stroke and death in patients who underwent embolization only. Events were identified through in-person neurologic follow-up visits performed at 6-month intervals during the first 2 years and annually, with telephone contact every 6 months thereafter. All event-related data were reviewed by independent adjudicators.

RESULTS: Among 30 patients who had embolization planned, 26 underwent embolization only. A total of 13 stroke events were reported in the follow-up period among 26 subjects (ischemic, hemorrhagic, or both in 4, 7, and 2 subjects, respectively). The adverse event occurred after the first embolization in 11 of 13 patients. One patient had a major motor deficit, and 2 patients developed major visual field deficits. One event was fatal. The modified Rankin Scale score was 0-2 at last follow-up in 11 of the 12 stroke survivors. Estimated stroke-free survival was $46 \%$ at 12 months.

CONCLUSIONS: Although the rates of stroke and/or death were high in patients treated with embolization only in ARUBA, the rates of favorable outcomes following stroke were high during follow-up.

ABBREVIATION: BAVM = brain arteriovenous malformations

A Randomized Trial of Unruptured Brain Arteriovenous Malformations (ARUBA) reported the risk of death and symptomatic stroke in 223 patients with an unruptured brain arteriovenous malformation (BAVM) randomized to either medical management alone or medical management with interventional

Received August 23, 2019; accepted after revision January 20, 2020.

From the Zeenat Qureshi Stroke Institute (A.I.Q., O.S., S.S., I.L., J.L.), St. Cloud, Minnesota; Department of Neurology (A.I.Q., C.R.G.) and Division of Neurological Surgery (F.S.), University of Missouri, Colombia, Missouri; Department of Neurology (O.S.), University of Tennessee Health Science Center, Memphis, Tennessee; Department of Neurology (S.S.), JFK Medical Center, Edison, New Jersey; and Pakistan Emirates Military Hospital (J.L.), Rawalpindi, Pakistan.

Paper previously presented as poster at: Annual Meeting of the American Academy of Neurology, May 4-10, 2019; Philadelphia, Pennsylvania.

Please address correspondence to Adnan I. Qureshi, MD, University of Missouri, Department of Neurology, One Hospital Dr., CE507, Columbia, MO 6521; e-mail: qureshai@gmail.com

Indicates article with supplemental on-line tables.

http://dx.doi.org/10.3174/ajnr.A6443 therapy. ${ }^{1}$ For 114 patients allocated to interventional therapy, brain arteriovenous malformations were treated by neurosurgery alone $(n=5)$, embolization alone $(n=30)$, or radiation therapy alone $(n=31)$ or using a multimodal approach $(n=28)$. The study was discontinued after the Data and Safety Monitoring Board appointed by the National Institute of Neurological Disorders and Stroke of the National Institutes of Health recommended halting randomization because the composite end point of death or symptomatic stroke had occurred in $10.1 \%$ patients in the medical management group compared with $30.7 \%$ in the interventional therapy group, which exceeded the prespecified stopping boundary.

Questions have been raised regarding the high-rate use of primary (rather than adjunct) endovascular treatment in the ARUBA trial, and other authors have recommended an indepth analysis of adverse events in patients who were treated with embolization only in the trial. ${ }^{2,3}$ Embolization as a primary treatment for BAVM has been reported in approximately 
$2 \%-10 \%$ of the patients in other studies, which is much lower than the $26 \%$ use rate in ARUBA. ${ }^{4,5}$ Furthermore, considerable variation in the rates of severe complications with embolization (overall, 6.6\%; range, $0 \%-28 \%$ ) was seen between studies for unruptured and ruptured BAVMs in a meta-analysis, highlighting the role of study-specific in-depth analysis. ${ }^{6}$

We performed an in-depth analysis of the results of endovascular embolization only in patients with BAVMs treated in ARUBA trial.

\section{MATERIALS AND METHODS}

We acquired the public use of ARUBA dataset files from the National Institute of Neurological Disorders and Stroke clinical research archives. The design of the ARUBA trial has been described previously. ${ }^{1}$ The trial was a prospective, multicenter, randomized controlled trial involving 39 active clinical sites in 9 countries. All patients included were 18 years of age or older with an unruptured BAVM diagnosed by conventional angiography, MR imaging or MR angiography, or CT or CT angiography, with no imaging evidence of previous BAVM-related intracerebral hemorrhage or any previous interventional treatment attempt (endovascular, surgical, radiation therapy), or who were considered untreatable by the local investigators.

Patients who had concomitant vascular or brain disease that interfered with/or contraindicated any interventional therapy type (stenosis/occlusion of neck artery) or known allergy to iodine contrast agents were excluded. The trial excluded patients with multifocal BAVMs, arteriovenous or spinal fistula, vein of Galen type malformation, cavernous malformation, dural arteriovenous fistula, developmental venous anomaly, neurocutaneous syndrome such as cerebroretinal angiomatosis (von Hippel-Lindau syndrome), encephalo-trigeminal syndrome (Sturge-Weber) or Wyburn-Mason syndrome, Moyamoyatype changes, or hereditary hemorrhagic telangiectasia (OslerWeber-Rendu disease).

Participating sites had experience with the management of at least 10 BAVMs per year, the presence of a multidisciplinary arteriovenous malformation treatment team, and documented academic interest in BAVM research. The choice of endovascular treatment in patients allocated to the interventional therapy group was made by local ARUBA investigators as the technique to achieve complete eradication of the BAVM. Baseline imaging (MR imaging or MR angiography, CT or CT angiography, or conventional angiography) was collected after enrollment for each patient. Additionally, all baseline imaging studies were subject to independent centralized adjudication for diagnostic accuracy. Lesion eradication was confirmed on the basis of conventional angiography and central adjudication.

Patients were actively screened for the possibility of new stroke, neurologic deficits, seizures, headaches, or any other clinically important event during in-person neurologic followup visits scheduled at 6-month intervals during the first 2 years and then annually or with telephone contact, which was performed every 6 months to supplement annual clinic visits after the first 2 years of randomization. Stroke was defined as a clinically symptomatic event (any new focal neurologic deficit, seizure, or new-onset headache) that was associated with imaging findings of hemorrhage or infarction. Hemorrhage was defined as fresh intracranial blood on head CT or MR imaging or in the CSF. Infarction was defined as a new ischemic lesion on cranial CT or MR imaging (diffusion-weighted, T2weighted, or fluid-attenuated inversion recovery MR imaging). Any imaging studies related to neurologic adverse events were systematically collected in electronic format and included in the material for independent clinical event adjudication. All primary and secondary outcome events were adjudicated by an independent panel of 4 distinguished academic community members (neurology, interventional neuroradiology, neurosurgery, and radiosurgery). ${ }^{7}$ If a stroke related to a BAVM occurred, the patient was seen within 48 hours of the event by a designated neurologist, and the data coordinating center was notified within 72 hours. The decision as to whether to continue with treatment and plans for the type of treatment were made by the treating team.

We selected all the patients in whom endovascular treatment was the only treatment used and reviewed the individual data elements in the public use trial dataset. For patients who developed a stroke event, we collected age and sex, BAVM location and size, Spetzler-Martin grade, number of embolizations, symptoms, stroke subtype (ischemic or hemorrhage), time interval between embolization and the stroke event, and the modified Rankin Scale score at last follow-up. We reviewed the description of events and classified them into visual field deficits, motor deficits, level of consciousness deficits, and others. Visual field deficits were classified as major if complete hemianopsia was reported. Motor deficits were classified as major if hemiplegia or both upper and lower extremities were involved. We also classified a deficit as major if at follow-up, the modified Rankin Scale score was $>2$.

\section{Statistical Analysis}

The analysis was predominantly descriptive. We calculated the 1month rate of stroke and death as the proportion of patients who experienced the event relative to total number at risk. We compared the baseline, clinical, and angiographic variables of patients who were treated using embolization only according to whether they had a stroke event. We used the $\chi^{2}$ test and ANOVA for categoric and continuous variables, respectively. Time to stroke event or death after embolization or the last known follow-up period in stroke-free patients was used to estimate the proportion of patients who would be alive and stroke-free at 12 months using Kaplan-Meier analysis and life tables. All data were analyzed using SPSS Statistics for Windows, Version 23.00, 64-bit edition (IBM, Armonk, New York).

\section{RESULTS}

Thirty patients of 116 randomized to interventional treatment were scheduled to have embolization. Of the 30 patients with intended embolization, only 26 patients underwent embolization. In 1 patient, the diagnosis of BAVM was not confirmed on the pretreatment angiogram. In 3 patients, the microcatheter could not be placed in the target feeders for safe or effective 
embolization. Of the 26 patients, embolization was performed using Onyx (Covidien, Irvine, California) in 21 patients; Histoacryl (Braun, Melsungen, Germany) in 3 patients; and $\mathrm{N}$ butyl cyanoacrylate and Glubran Tiss (Aspide Medical, La Talaudiére, France) in 1 patient each. The mean age of subjects was $43.7 \pm 11.1$ years; 14 were men. The initial presentation was seizure with headache $(n=3)$, headache alone $(n=6)$, seizure alone $(n=11)$, focal deficits with seizure $(n=1)$, and focal deficits alone $(n=3)$. The BAVM was graded as Spetzler-Martin grades I, II, III, and IV in 7, 10, 8, and 1 subjects, respectively. The baseline clinical and angiographic characteristics of the subjects are presented in On-line Table 1. The average number of embolizations per subject was 3.2 (range, 1-9).

The median follow-up period after embolization was $11.8 \pm$ 9.4 months (range, $0-30$ months). A total of 13 stroke events were reported during the follow-up period among 26 subjects (69.8 per 1000 person-days follow-up). The strokes were reported as ischemic, hemorrhagic, or both in 4,7 , and 2 subjects, respectively. The adverse event occurred after first embolization in 11 of 13 patients.

The proportion of women among those who experienced stroke was significantly higher (69.2\% versus $30.8 \%, P=.02)$. There was a higher proportion of subjects who developed stroke in subjects with Spetzler-Martin grades III and IV. The maximum BAVM size (anterior-posterior length) was nonsignificantly greater in patients who had a stroke (26.4 \pm $14.2 \mathrm{~mm}$ versus $19.9 \pm 6.3 \mathrm{~mm}, P=.1$ ), and the side of the lesion was not associated with the occurrence of stroke (Online Table 1). There appeared to be a higher prevalence of unrelated aneurysms and deep venous drainage among patients with stroke events. There was no difference in the mean number of embolizations in those who had stroke events (3.6 \pm 2.5 versus $2.7 \pm 1.4, P=.3$ ).

A review of description of events demonstrated that episodic headache, bruit in the ear, or unilateral myosis occurred in 3 patients without any other neurologic deficits. One stroke event was fatal. Of the 12 stroke survivors, the modified Rankin Scale score was $0-2$ at last follow-up in 11 subjects. One patient had a major motor deficit, and 2 patients developed major visual field deficits. The fatal stroke occurred in a 61-year-old woman who underwent embolization with Onyx for reduction of the BAVM nidus before stereotactic radiosurgery (On-line Table 2). The subject developed new-onset coma secondary to intracerebral hemorrhage 9 days after embolization and died a day later subsequent to withdrawal of care. Two patients developed homonymous hemianopsia deficits immediately postembolization with MR imaging demonstrating infarction in relevant distributions. Two others developed partial visual field deficits. One patient with a partial visual field had concurrent occipital headaches, and a second patient had skew deviation and partial upper gaze palsy. Three patients developed intraparenchymal hemorrhages, of which 1 was only associated with transient headache and the other 2 were associated with hemiplegia. Two patients developed upper extremity weakness postembolization (1 preceded by seizures). The estimated stroke-free survival was $46 \%$ at 12 months.

\section{DISCUSSION \\ Key Results}

We provide a detailed description of the stroke events that occurred in patients in the ARUBA trial who underwent embolization only. Stroke or death or both within 1 month following the procedure occurred in $15.4 \%$ of patients. Four patients met the definition of having a major neurologic deficit. Intracerebral hemorrhage occurred in 9 of 13 patients with a stroke event. One stroke event was fatal. One patient developed a major motor deficit, and 2 patients developed major visual field deficits. In the patient who developed a major motor deficit, the deficit occurred after 101 days, so it may be considered related to the disease process rather than the procedure. Some events were minor, such as episodic headache, bruit in the ear, or unilateral myosis occurring in 3 patients without any other neurologic deficits. The modified Rankin Scale score was 0-2 at last follow-up in 11 of the 12 stroke survivors. Therefore, major disability was infrequent among patients who actually had a stroke postembolization.

\section{Limitations}

This is a retrospective analysis of prospectively collected data. The issues regarding patient and procedure selection within the ARUBA trial have been mentioned earlier. Without in-depth procedural data, the relationship between individual components of the procedure and stroke and/or death cannot be determined. Furthermore, issues like intraprocedural anticoagulation and postprocedural blood pressure control could not be evaluated. We included patients who underwent only embolization, but it is possible that in some patients, additional treatment such as surgical excision or radiation therapy would have been performed in the absence of any stroke or death.

\section{Interpretation}

Certain aspects are important to understand before interpretation of the results. All the patients analyzed underwent embolizationonly; therefore, our analysis avoids contamination by the consequences of surgery or radiosurgery. However, in some patients, additional surgery or radiation therapy may have been planned but was not performed, either due to good results or complications associated with embolization. We did not have data regarding the percentage of angiographic obliteration following the embolization, which prevented us from performing more indepth analysis.

The rates of stroke events appeared higher than in the Brain Arteriovenous Malformations Embolization with Onyx (BRAVO) study, which included patients with BAVMs treatable using an endovascular approach who were included if the treatment was partially or completely performed using Onyx. ${ }^{8}$ Patients who had experienced recent intracranial bleeding (in the month before the first embolization session) were excluded. Posttreatment intracerebral hemorrhage occurred in 10 of 117 patients who had undergone 237 embolization sessions. Nonhemorrhagic deficits occurred in 16 of 117 patients ( 9 were transient). The overall rate of any stroke event was $26(22 \%)$ of 117 patients treated. Five (4.3\%) patients died due to treatment-related complications similar to the $1(3.8 \%)$ of 26 patients in the ARUBA trial. However, the rate of major stroke was $5.1 \%$ in the BRAVO trial and $15.3 \%$ in the ARUBA trial (there 
were some differences in defining major stroke between the trials). There were 2 important differences between the 2 trials: The rate of patients with Spetzler-Martin AVM grades IV (22\% versus $4 \%$ ) and ruptured BAVM (34\% versus none) was higher in the BRAVO trial. Most interesting, the rate of postembolization intracerebral hemorrhage was higher in unruptured AVMs (11.7\%) than in ruptured AVMs (2.5\%). Similarly, total obliteration was less common in unruptured AVMs (18.7\%) than in ruptured AVMs (32.5\%).

A single-center retrospective review of patients with unruptured BAVMs who met the inclusion criteria of ARUBA and underwent primary Onyx embolization ${ }^{9}$ reported a 1-month rate of $13 \%$ for stroke or death and $3 \%$ for death following the procedure. Six of the 8 stroke events or death were intracerebral hemorrhages. It is possible that primary embolization of unruptured BAVMs is associated with a higher risk than ruptured BAVMs. There are certain attributes of BAVMs that are more prevalent in patients with ruptured BAVMs, such as intranidal fistulas ${ }^{10}$ and flow-related aneurysms, ${ }^{11}$ deep venous drainage, ${ }^{10}$ small nidus size, ${ }^{12}$ high feeding mean arterial pressure, ${ }^{12}$ deep location, ${ }^{13}$ venous stenosis, ${ }^{14}$ a single draining vein, ${ }^{15}$ and slow filling of feeding arteries. ${ }^{16}$ It remains unclear whether certain angiographic characteristics in unruptured BAVMs predispose to an increased risk associated with embolization. Some studies have not found such a relationship. ${ }^{17,18}$

There is no consensus regarding the interpretation of the results of the ARUBA trial. Opinions vary as follows: 1) no implications because the trial design was full of flaws and not representative of current practices; ${ }^{3}$ 2) a more limited role of embolization with more emphasis on surgery and radiation therapy; ${ }^{19-21}$ and 3) a limited role for any treatment technique with greater emphasis on conservative management in the treatment of unruptured BAVMs. ${ }^{1}$ The American Heart Association/American Stroke Association Scientific Statement acknowledges that the optimal approach to management of unruptured BAVMs remains a subject of debate because of insufficient high-quality, consistent evidence about the lifetime risks of intracerebral hemorrhage and its predictors and the complications associated with treatment. ${ }^{22}$

\section{Generalizability}

The implications of this analysis need to be discussed. The analysis provides more details regarding the stroke events and associated characteristics of patients and BAVMs. The analysis is an important step in understanding how to modify current practices when choosing embolization for unruptured BAVMs. Minor stroke events perhaps may not have the same significance compared with major events (in regard to disability and resource use), yet they may be classified as stroke events. ${ }^{23}$ In the ARUBA trial, only 2 of 13 stroke events resulted in moderate-to-severe disability, categorized by a modified Rankin Scale score of $>2$ at last follow-up. Minor postembolization deficits may be acceptable if the treatment is effective in preventing major stroke and disability during follow-up, ${ }^{24}$ considering that the incidence of firstever hemorrhage in untreated patients with BAVM during follow-up was as follows: $0-9$ years, $4.6 \%$; 30-39years, $21 \%$; and 60-69 years, $40.0 \%$ in 1 study. The first intracranial hemorrhage was fatal in $4.6 \%$ of the patients. Approximately $28 \%$ of treated and untreated patients had a moderate-to-severe disability by the
Oxford Handicap Scale at a mean follow-up of 10 years. ${ }^{25,26}$ Primary or recurrent hemorrhage in patients with BAVM resulted in moderate-to-severe disability (modified Rankin Scale score, $>2$ ) in approximately $40 \%$ of patients. Crawford et $\mathrm{al}^{27}$ reported that there was a $42 \%$ risk of intracerebral hemorrhage, a $29 \%$ risk of death, an $18 \%$ risk of epilepsy, and a $27 \%$ risk of having a neurologic handicap by 20 years after diagnosis in patients with BAVMs without treatment.

\section{CONCLUSIONS}

A simulation analysis demonstrated that the risk of intervention in unruptured BAVMs would have to be reduced by $50 \%$ to achieve equivalence and by $80 \%$ to achieve superiority to medical management on the basis of the results of ARUBA trial. ${ }^{28}$ Newer embolization techniques have the promise of increasing the efficacy of treatment, though safety and long-term effectiveness remain unclear. There are some encouraging initial data supporting the role of targeted embolization focusing on selected regions such as intranidal aneurysms or high-flow fistulas ${ }^{29-31}$ in achieving a better balance in the risk-benefit ratio. A transvenous approach and embolization of BAVMs that are supplied by very narrow and tortuous arterial pedicles may have the potential to increase the curative rates. ${ }^{32,33}$ The American Heart Association/ American Stroke Association Scientific Statement ${ }^{22}$ recommends further clinical studies to investigate the reproducibility of the findings of ARUBA and to investigate whether the balance of risk between conservative management and intervention is different in specific groups. Certain trials are already underway such as the Treatment of Brain AVMs (TOBAS) study and the Transvenous Approach for the Treatment of Cerebral Arteriovenous Malformations (TATAM) study to add additional information regarding the role of embolization in BAVM treatment.

\section{REFERENCES}

1. Mohr JP, Parides MK, Stapf C, et al; international ARUBA investigators. Medical management with or without interventional therapy for unruptured brain arteriovenous malformations (ARUBA): a multicentre, non-blinded, randomised trial. Lancet 2014;383:61421 CrossRef Medline

2. Russin J, Spetzler R. Commentary: the ARUBA trial. Neurosurgery 2014;75:E96-97 CrossRef Medline

3. Bambakidis NC, Cockroft KM, Hirsch JA, et al. The case against a randomized trial of unruptured brain arteriovenous malformations: misinterpretation of a flawed study. Stroke 2014;45:2808-10 CrossRef Medline

4. Link TW, Winston G, Schwarz JT, et al. Treatment of unruptured brain arteriovenous malformations: a single-center experience of 86 patients and a critique of the A Randomized Trial of Unruptured Brain Arteriovenous Malformations (ARUBA) Trial. World Neurosurg 2018;120:e1156-62 CrossRef Medline

5. Rutledge WC, Abla AA, Nelson J, et al. Treatment and outcomes of ARUBA-eligible patients with unruptured brain arteriovenous malformations at a single institution. Neurosurg Focus 2014;37:E8 CrossRef Medline

6. van Beijnum J, van der Worp HB, Buis DR, et al. Treatment of brain arteriovenous malformations: a systematic review and meta-analysis. JAMA 2011;306:2011-19 CrossRef Medline 
7. Mohr JP, Moskowitz AJ, Parides M, et al. Hull down on the horizon: A Randomized trial of Unruptured Brain Arteriovenous malformations (ARUBA) trial. Stroke 2012;43:1744-45 CrossRef Medline

8. Pierot L, Cognard C, Herbreteau D, et al. Endovascular treatment of brain arteriovenous malformations using a liquid embolic agent: results of a prospective, multicentre study (BRAVO). Eur Radiol 2013;23:2838-45 CrossRef Medline

9. Singfer U, Hemelsoet D, Vanlangenhove P, et al. Unruptured brain arteriovenous malformations: primary Onyx embolization in ARUBA (A Randomized Trial of Unruptured Brain Arteriovenous Malformations)-eligible patients. Stroke 2017;48:3393-96 CrossRef Medline

10. Marks MP, Lane B, Steinberg GK, et al. Hemorrhage in intracerebral arteriovenous malformations: angiographic determinants. Radiology 1990;176:807-13 CrossRef Medline

11. Willinsky R, Lasjaunias $\mathrm{P}$, Terbrugge $\mathrm{K}$, et al. Brain arteriovenous malformations: analysis of the angio-architecture in relationship to hemorrhage (based on 152 patients explored and/or treated at the Hopital de Bicetre between 1981 and 1986). J Neuroradiol 1988;15:225-37 Medline

12. Kader A, Young WL, Pile-Spellman J, et al. The influence of hemodynamic and anatomic factors on hemorrhage from cerebral arteriovenous malformations. Neurosurgery 1994;34:801-07; discussion 807-08 CrossRef Medline

13. Turjman F, Massoud TF, Vinuela F, et al. Correlation of the angioarchitectural features of cerebral arteriovenous malformations with clinical presentation of hemorrhage. Neurosurgery 1995;37:856-60; discussion 860-62 CrossRef Medline

14. Nataf F, Meder JF, Roux FX, et al. Angioarchitecture associated with haemorrhage in cerebral arteriovenous malformations: a prognostic statistical model. Neuroradiology 1997;39:52-58 CrossRef Medline

15. Shi X, Wang Z, Yu C. An analysis of the correlation between angiographic and clinical findings in cerebral arteriovenous malformations. Chin Med Sci J 1993;8:35-37 Medline

16. Asadi $\mathrm{H}, \mathrm{Kok} \mathrm{HK}$, Looby $\mathrm{S}$, et al. Outcomes and complications after endovascular treatment of brain arteriovenous malformations: a prognostication attempt using artificial intelligence. World Neurosurg 2016;96:562-69.e561 CrossRef Medline

17. Ledezma CJ, Hoh BL, Carter BS, et al. Complications of cerebral arteriovenous malformation embolization: multivariate analysis of predictive factors. Neurosurgery 2006;58:602-11; discussion 602-11 CrossRef Medline

18. Lv X, Wu Z, Jiang C, et al. Complication risk of endovascular embolization for cerebral arteriovenous malformation. Eur J Radiol 2011;80:776-79 CrossRef Medline

19. Karlsson B, Jokura H, Yang HC, et al. The NASSAU (New ASSessment of cerebral Arteriovenous malformations yet Unruptured) analysis: are the results from the ARUBA trial also applicable to unruptured arteriovenous malformations deemed suitable for gamma knife surgery? Neurosurgery 2018;85:E118-24 CrossRef Medline
20. Wong J, Slomovic A, Ibrahim G, et al. Microsurgery for ARUBA trial (A Randomized Trial of Unruptured Brain Arteriovenous Malformation)-eligible unruptured brain arteriovenous malformations. Stroke 2017;48:136-44 CrossRef Medline

21. Ding D, Starke RM, Kano H, et al. Radiosurgery for cerebral arteriovenous malformations in A Randomized Trial of Unruptured Brain Arteriovenous Malformations (ARUBA)-eligible patients: a multicenter study. Stroke 2016;47:342-49 CrossRef Medline

22. Derdeyn CP, Zipfel GJ, Albuquerque FC, et al; American Heart Association Stroke Council. Management of brain arteriovenous malformations: A Scientific Statement for Healthcare Professionals from the American Heart Association/American Stroke Association. Stroke 2017;48:e200-24 CrossRef Medline

23. Staubach S, Hein-Rothweiler R, Hochadel M, et al. Predictors of minor versus major stroke during carotid artery stenting: results from the Carotid Artery Stenting (CAS) registry of the Arbeitsgemeinschaft Leitende Kardiologische Krankenhausarzte (ALKK.). Clin Res Cardiol 2014;103:345-51 CrossRef Medline

24. ApSimon HT, Reef $\mathrm{H}$, Phadke RV, et al. A population-based study of brain arteriovenous malformation: long-term treatment outcomes. Stroke 2002;33:2794-800 CrossRef Medline

25. Halim AX, Johnston SC, Singh V, et al. Longitudinal risk of intracranial hemorrhage in patients with arteriovenous malformation of the brain within a defined population. Stroke 2004;35:1697-702 CrossRef Medline

26. van Beijnum J, Lovelock CE, Cordonnier C, et al; SIVMS Steering Committee and the Oxford Vascular Study. Outcome after spontaneous and arteriovenous malformation-related intracerebral haemorrhage: population-based studies. Brain 2009;132:537-43 CrossRef Medline

27. Crawford PM, West CR, Chadwick DW, et al. Arteriovenous malformations of the brain: natural history in unoperated patients. $J$ Neurol Neurosurg Psychiatry 1986;49:1-10 CrossRef Medline

28. Joyce C, Gomez CR. Reimagining ARUBA: theoretical optimization of the treatment of unruptured brain arteriovenous malformations. J Stroke Cerebrovasc Dis 2018;27:3100-07 CrossRef Medline

29. Sun $\mathrm{Y}$, Jin H, Li Y, et al. Target embolization of associated aneurysms in ruptured arteriovenous malformations. World Neurosurg 2017;101:26-32 CrossRef Medline

30. Sahlein DH, Mora P, Becske T, et al. Nidal embolization of brain arteriovenous malformations: rates of cure, partial embolization, and clinical outcome. J Neurosurg 2012;117:65-77 CrossRef Medline

31. Le Feuvre D, Taylor A. Target embolization of AVMs: identification of sites and results of treatment. Interv Neuroradiol 2007;13:389-94 CrossRef Medline

32. Iosif C, Mendes GA, Saleme S, et al. Endovascular transvenous cure for ruptured brain arteriovenous malformations in complex cases with high Spetzler-Martin grades. J Neurosurg 2015;122:1229-38 CrossRef Medline

33. Wang MZ, Qiu HC, Wang S, et al. A new technique for transvenous embolization of brain arteriovenous malformations in hybrid operation. Chin Med J 2018;131:2993-96 CrossRef Medline 